\title{
Application of a performance-displacement based method for the seismic assessment of earth dams
}

\author{
Ismael De la Paz-Bonilla ${ }^{1}$ and Aidcer L. Vidot-Vega ${ }^{2^{*}}$
}

\author{
*Correspondence: \\ aidcer.vidot@upr.edu \\ ${ }^{2}$ University of Puerto Rico \\ at Mayaguez, Call Box 9000, \\ Mayaguez, PR 00681, USA \\ Full list of author information \\ is available at the end of the \\ article
}

\begin{abstract}
This paper presents the application of a performance-displacement based assessment methodology to characterize the seismic response under several damage or performance-based scenarios of an earth dam. In the applied method, the system displacements are related to spectral accelerations and moment magnitudes in order to evaluate performance or damage scenarios. The earth dam selected for this study is the Carite Dam in Guayama, Puerto Rico. This embankment dam was built in 1913 in different phases with a raised embankment crest for flooding control in 1995. A finite element of the dam was developed to perform several incremental dynamic analyses. The dam geometry and materials properties were estimated based on extensive review of borings logs and technical reports provided by the administrators of the dam. The dynamic analyses were accomplished using seismic ground records with response spectrum made compatible with the design response spectrum from the ASCE-10 standard. Crest horizontal displacements were obtained from the dynamic analyses for different incremental factors and used to estimate moment magnitude and epicentral distances needed to attain the displacement limits.
\end{abstract}

Keywords: Earth dam, Moment magnitude, Epicentral distance, Displacement-based assessment, Damage limits

\section{Background}

Performance-based seismic design or assessment has been developed for over more than 2 decades. According to the SEAOC Vision 2000 [14], performance-based seismic engineering consists of a set of engineering procedures for the design and construction of structural systems to achieve predictable levels of performance in response to specified level of hazards, within definable levels of reliability. In terms of geotechnical engineering a performance based design or assessment of earth and embankment dams involves larger number of probabilistic considerations that can be sometimes cumbersome. Several standards have established some metrics for performance-based assessment of dams which are mostly based on acceptable levels of damage in relation with different design level earthquakes. For example, according to Wieland [18] the ICOLD [7] establishes the performance criteria for a dam based on several design earthquake intensities. The dam body should be able to sustain no structural damage under an Operational Basis Earthquake and structural damage is accepted as long as the stability of the dam is

(c) The Author(s) 2017. This article is distributed under the terms of the Creative Commons Attribution 4.0 International License (http://creativecommons.org/licenses/by/4.0/), which permits unrestricted use, distribution, and reproduction in any medium, provided you give appropriate credit to the original author(s) and the source, provide a link to the Creative Commons license, and indicate if changes were made. 
ensured and there is no uncontrolled release of water from the reservoir causing flooding in the downstream region of the dam under a Safety Evaluation Earthquake (SEE). Wieland et al. [19] indicates that performance criteria or specifications of acceptable damage under SEE ground motions are poorly defined and considering these in safety evaluations requires considerable engineering judgment. FEMA 65 [5] and FEMA 1025 [6] both provide federal guidelines for the risk assessment and dam safety and are similar to the ICOLD guidelines. They provide guides that relate probable damage scenarios to different design earthquake levels.

Nevertheless, several investigators in the area of geotechnical engineering are doing an effort to provide rational methodologies using concepts of performance-based design in a simplified way for the complementation of existing methodologies such as (a) traditional pseudo-static analyses, (b) displacement based (Newmark or sliding block method), and (c) dynamic stress-deformation numerical analyses. For example, Papadimitriou et al. [12] and Andrianopoulos et al. [1] have proposed a methodology to estimate seismic coefficients $\left(k_{h \max }\right)$ for performance-based design of earth dams and tall embankments. In this method, the $k_{h \max }$ is estimated as a function of PGAcrest. According to Andrianpoulos et al. [1] existing methodologies for estimating $\mathrm{k}_{\mathrm{hmax}}$ for pseudostatic analyses were not proved stand-alone and sufficiently accurate to really assess seismic performance or damage measurements in earth dams. However, they generated a database of $\mathrm{k}_{\mathrm{hmax}}$ that could be used to establish a stand-alone methodology. These authors [12] understand that there is currently no methodology based on performancebased concepts that can take into account significant parameters such as the intensity and frequency content of excitation, exact geometry of the potential sliding mass upstream or downstream, foundation conditions ("shear wave velocity $250-1500 \mathrm{~m} / \mathrm{s}$ "), reservoir impounded, and existence stabilized berms for estimation estimating seismic coefficient for earth dams and tall embankment and assess damage potentials.

Mehaand and Vahedifard [9] also focused their research in performance-based oriented methods for earth dams and embankments. They based their research on the analyses of observed displacements after earthquake shaking from 122 cases compared with fifteen simplified sliding blocks models based on empirical equations available in the literature. According to these investigators, predicted displacements from the fifteen simplified block models or empirical equations were less than the observed displacement for the majority of the case histories. In some cases the observed and predicted displacements varied from more than $1 \mathrm{~m}$, which constitutes a potential awareness for designers in the engineering practice. The results from this research established the need to have better performance- assessment tools for earth dams to evaluate displacements at different damage levels. All of these previous investigations motivate part of this research. To try to fill out a gap in the area of performance-based assessment of earth dams, this research used the principles of displacement-based design and assessment to determine minimum levels of seismic demand to achieve a prescribed displacement limit state or vice versa. Such an investigation is useful from the perspective of identifying the relative magnitude of an earthquake and corresponding dam to epicenter distance that are required to achieve prescribed levels of damage. This paper explores the use of an existing methodology to determine minimum moment magnitude and epicentral distances needed to attain certain limit state based on displacements. The methodology 
was applied to a case study of an earth dam located in Guayama, Puerto Rico. A finite element of the case study dam was developed in QUAKE/W (GEOSLOPE) to obtain displacements required to reach different damage levels and to apply the displacement based methodology.

\section{Application of a performance displacement-based methodology}

This section describes the performance-displacement based methodology that was applied to evaluate different damage scenarios in the case study dam. Vidot-Vega [16] explored the use of direct performance-displacement based methods in conjunction with code provisions (e.g. ASCE or FEMA) to determine the design earthquake that will impact a particular limit or damage state for RC buildings. This methodology was explored in this study to evaluate damage scenarios in the case study dam. In this method, the system displacements are related to spectral accelerations and moment magnitudes in order to evaluate performance or damage scenarios. In order to relate system displacements to spectral accelerations, it is necessary to obtain spectral displacements using the design response spectrum code equations (e.g. [3], Eq. 1). Thus, the period ( $T)$ in Eq. (1) is substituted by the corner period $\left(T_{c}\right)$ and then is divided by the square of the frequency $(\omega)$ of the system (assuming steady sinusoidal response) and multiplied by the gravitational acceleration (g) to obtain the spectral displacement as follows:

$$
\begin{aligned}
& S_{a}=\frac{S_{D 1}}{T} \text { for } T>T_{S} \\
& S_{D}=\frac{S_{D 1}}{T_{c} \omega^{2}} g ; \quad \omega=2 \pi / T_{c} \\
& S_{D}=\frac{S_{D 1}}{4 \pi^{2}} T_{c} g
\end{aligned}
$$

The corner period $\left(T_{c}\right)$ is the period at which the displacement spectra has its maximum value after which it becomes essentially constant, or reducing. Several researches have proposed expressions to obtain the corner period. This research used the expression recommended by the NEHRP [10] to calculate the corner period, which is given by:

$$
T_{C}=10^{\left(-1.25+0.3 M_{w}\right)}
$$

Equation (4) is based on seismology theory and depends on the moment magnitude $\left(M_{w}\right)$ of the earthquake. Since the $T_{c}$ is determined at maximum displacement, combining Eqs. (3) and (4) allows to evaluate damage levels in terms of displacements and earthquake magnitudes. Substituting Eq. (3) into Eq. (4), the spectral displacement can be expressed in terms of $\left(M_{w}\right)$ as follows:

$$
\begin{aligned}
& S_{D}=\frac{S_{D 1}}{4 \pi^{2}} 10^{\left(-1.25+0.3 M_{w}\right)} . \\
& S_{D 1}=\frac{2}{3} S_{M 1} ; \quad S_{M 1}=F_{v} S_{1}
\end{aligned}
$$


In these equations, the parameters are the following (from [3]):

$S_{D 1}$ : The design, 5-percent-damped, spectral response acceleration parameter at a period of $1 \mathrm{~s}$ as defined in Eq. (6a).

$S_{M 1}$ : The maximum considered earthquake, 5-percent-damped, spectral response acceleration parameter at a period of $1 \mathrm{~s}$ adjusted for site class effects, which is given by Eq. (6b).

Then, combine Eqs. (5) and (6a, b) to get the Spectral Displacement $\left(S_{D}\right)$ in terms of the Site coefficient $\left(F_{v}\right)$ and $S_{1}$ (mapped earthquake acceleration at $1 \mathrm{~s}$ from code maps). The Site coefficient $\left(F_{v}\right)$ depends on the site class (soil properties) and was obtained in this research from Table 11.4-2 of [3]. The Spectral Displacement $\left(S_{D}\right)$ is given by Eq. (7).

$$
S_{D}=\frac{F_{V} S_{1}}{6 \pi^{2}} g\left[10^{\left(-1.25+0.3 M_{w}\right)}\right]
$$

In the Eq. (7) the spectral displacement can be substituted by the system displacement $\left(\Delta_{\text {sys }} / R_{\xi}\right)$ and can be solve by $S_{1}$ or $M_{w}$ to evaluate expected mapped earthquake accelerations or moment magnitudes that can generate a particular limit damage state based on displacements. $R_{\xi}$ is a reduction factor applied to the elastic displacement spectrum (5\%) to account for increased levels of damping in some cases $\left(R_{\xi}=1\right.$ for dams). Equation (8) was solved for $S_{1}$ and Eq. (9) was solved for $M_{w}$. Figure 1 explains this methodology graphically.

$$
\begin{aligned}
& S_{1}=\frac{\left(\Delta_{s y s} / \mathrm{R}_{\xi}\right) 6 \pi^{2}}{F_{v} g 10^{\left(-1.25+0.3 M_{w}\right)}} \\
& M_{w}=\left(\log \left[\frac{\left(\Delta_{s y s} / \mathrm{R}_{\xi}\right) 6 \pi^{2}}{\left(F_{v} S_{1} g\right)}\right]+1.25\right) / 0.3
\end{aligned}
$$

Faccioli et al. [4] have proposed an expression to obtain the peak spectral displacement, which is given by:

$$
\delta_{\max }=C_{S} \frac{10^{\left(M_{W}-3.2\right)}}{r}(\mathrm{~mm})
$$

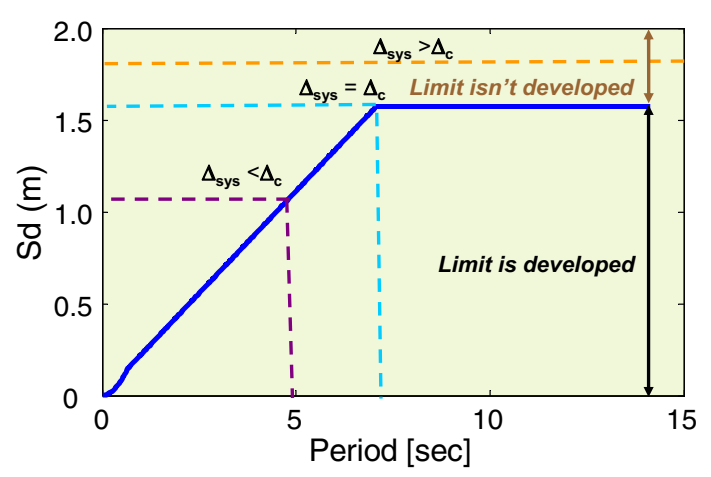

Fig. 1 Graphical representation of the methodology 


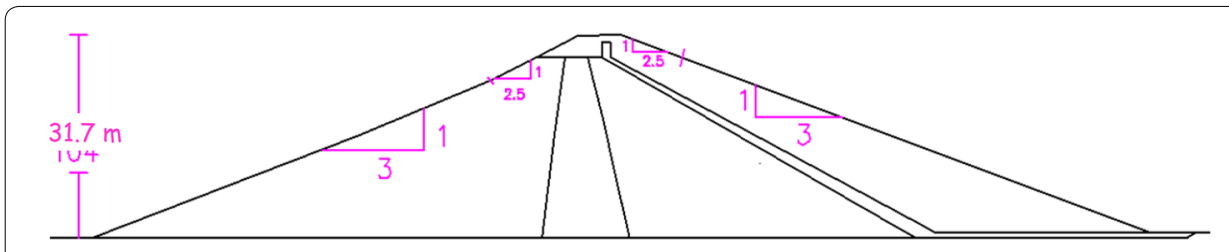

Fig. 2 Esquematic section of the Carite Earth Dam

where $r(\mathrm{~km})$ is the epicentral distance or nearest distance to the fault plane for a large earthquake, and $\mathbf{C}_{\mathbf{s}}$ are soil coefficients. Some recommended values for $\boldsymbol{C}_{\boldsymbol{s}}[13]$ are:

- Rock: $C_{s}=0.7$

- Firm Ground: $\boldsymbol{C}_{\boldsymbol{s}}=1.0$

- Intermediate Soil: $\boldsymbol{C}_{\boldsymbol{s}}=1.4$

- Very Soft Soil: $\boldsymbol{C}_{\boldsymbol{s}}=1.8$

Equation (10) can be solved for $r$ to obtain the epicentral distance and Mw needed to attain a certain displacement limit. For the case study dam, the parameters used were the following: $S_{1}=0.385 \mathrm{~g}, F_{v}=1.5$ and $C_{s}=1.4$. Next section presents the properties and geometry of the case study dam.

\section{Case study}

The Carite Dam was selected for this study. The Carite Dam was built in 1913 and it belongs to the district of Guayama, Puerto Rico. The lake covers an area of 123.8 ha, but the catchment area of the dam is 7.92 square miles. The height and length of the dam are 31.70 and $152 \mathrm{~m}$, respectively. The dam is $551 \mathrm{~m}$ above sea level and the waters of the Rio La Plata and some tributary streams supply it. The controlled water is used for irrigation and drinking water supply. The exceeding water is used for the three hydroelectric plants near Guayama. A raised embankment crest was recommended due to an existing loose soil in the downstream by Law Engineering Charlotte, North Carolina in May of 1992 based on several stability analyses. A new crest was constructed in 1995 to mitigate this loose soil that will remain in-place but confined and buttressed by the new embankment. From Fig. 2 it can be observed that the upper part of the dam has a slope of 1:2.5 and then it changes to 1:3 for protection of the downstream area.

\section{Soil properties for the FE model of Carite Dam}

The dam finite element (FE) model was developed using the boring logs provided by the Power Authority of Puerto Rico (administrator of the dam) in conjunction with the empirical equations. Since the only information available from the borings was the $\mathrm{N}$ value, empirical equations were used to compute shear wave velocities (Vs) and the shear modulus $(G)$ of the different soil layers. The empirical equations of Ohta and Goto [11] that related the $\mathrm{N}$ values to the shear wave velocities (Vs) were used. These equations are well documented in the literature and have been used in the engineering practice extensively. Figure 3 presents a picture of the finite element model showing the different soil layers in Quake/W. The model was divided using a total of eighteen soil layers and the 


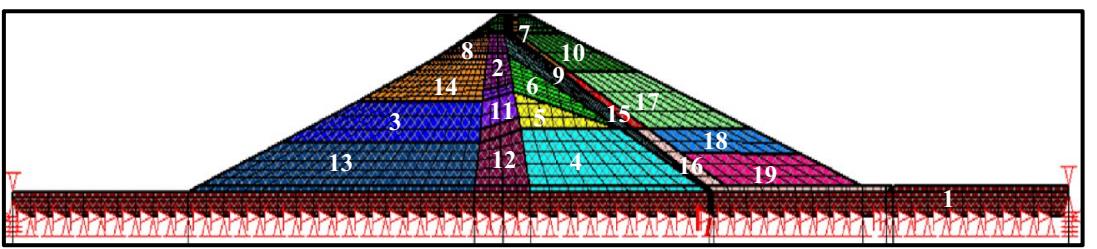

Fig. 3 Soil layer mesh in quake/W

properties (i.e. unit weight $\gamma$, cohesion $c$, internal friction angle $\phi$, shear wave velocity $V_{S}$, shear modulus $G$, and modulus of elasticity $E$ ) are shown in Table 1 . Ambient vibration tests were performed and the fundamental vibration period of the dam was found (around $0.31 \mathrm{~s}$ ). With the FE model of the dam, it was obtained a similar fundamental period which allows to validate the properties used in the model.

\section{Modeling considerations and dynamic analyses}

A 2D dam finite element model was developed in QUAKE/W program (GEOSLOPE). Plane strain elements were used in the model. The incremental dynamic analyses of Carite Dam were performed using the equivalent linear method. This method is based on the use of equivalent linear properties which are characterized by the shear modulus ( $G$ and Gmax) and damping ratio (६) for different soils. Gmax is the small-strain shear modulus. It is important to recognize, however, that the equivalent linear model is only an approximation of the actual nonlinear behavior of the soil. In this method the variation of the shear modulus of the soil with the cyclic shear strain is described by the G/ Gmax curve. At low strain amplitudes, the shear modulus is high, but it decreases as the strain amplitude increases [8]. In other hand, the damping ratio increases as the shear strain also increases. Several researches have proposed different G/Gmax reduction and damping curves to be use in equivalent linear analyses. For the analyses of Carite Dam, the Vucetic and Dobry [17] curves were used. Figure 4 show the G/Gmax reduction and damping curves used in the analyses to approximate the nonlinear behaviour of the different soil layers in the dam. These curves are function of the cyclic shear strain. The soil layers in the dam are then defined by the shear modulus and damping as a function of strain, the thickness, and unit weight.

Accelerations and displacements were recorded during the analyses. The incremental dynamic analyses were performed varying the peak ground accelerations with factors from 0.5 to 1.5 . The results obtained from the dynamic analyses were recorded for a total of 10 nodes that were considered important. Figure 5 shows the location of these nodes. The nodes $(895,1130,1218,1322,1351$ and 1374) are located at the downstream part of the dam and nodes $(668,679,686$ and 700$)$ at the core. The core horizontal displacements were used for the application of the displacement based methodology since these displacmenet were higher that the ones obtained at the downstream part of the dam.

\section{Selection of seismic ground motions}

A search for earthquake records was realized at the PEER database. The ASCE design spectrum with spectral acceleration parameters obtained for the Carite site was used as 
Table 1 P450s with chloroplast or mitochondiral targeting signals

\begin{tabular}{c|c|c|c|c|c|c|c}
\hline $\begin{array}{c}\text { GeoStudio } \\
\#\end{array}$ & Description & Colors & $\boldsymbol{V}\left(\mathrm{kN} / \mathrm{m}^{3}\right)$ & $\boldsymbol{c}\left(\mathrm{kN} / \mathrm{m}^{2}\right)$ & $\boldsymbol{\varphi}^{\circ}$ & $\boldsymbol{V}_{\boldsymbol{s}}(\mathrm{m} / \mathrm{s})$ & $\boldsymbol{G}\left(\mathrm{kN} / \mathrm{m}^{2}\right)$ \\
\hline \hline 1 & Hard Layer & & 25.91 & 478.75 & 45 & 760.06 & 1524441.07 \\
\hline 2 & Core of Red Clay & & 18.78 & 34.47 & 15 & 173.17 & 57282.58 \\
\hline 11 & Core of Red Clay & & 18.78 & 34.47 & 15 & 235.06 & 105769.45 \\
\hline 12 & Core of Red Clay & & 18.78 & 34.47 & 15 & 255.79 & 125246.34 \\
\hline 3 & Lower Upstream Shell & & 19.63 & 0.00 & 30 & 248.78 & 123700.46 \\
\hline 13 & Lower Upstream Shell & & 19.63 & 0.00 & 30 & 284.45 & 161821.12 \\
\hline 4 & Lower Downstream Shell & & 19.63 & 0.00 & 30 & 294.82 & 173946.53 \\
\hline 5 & Perched Water Layer & & 19.63 & 35.91 & 15 & 236.28 & 111541.82 \\
\hline 6 & Upper Downstream Shell & & 19.63 & 35.91 & 15 & 211.28 & 89327.92 \\
\hline 7 & Downstream "Loose" Zone & & 19.63 & 35.91 & 15 & 187.80 & 70559.87 \\
\hline 8 & Upper Upstream Shell & & 19.63 & 35.91 & 15 & 192.07 & 73691.55 \\
\hline 14 & Upper Upstream Shell & & 19.63 & 35.91 & 15 & 227.44 & 103498.74 \\
\hline 9 & Drainage Material & & 19.63 & 0.00 & 37 & 324.09 & 210051.04 \\
\hline 15 & Drainage Material & & 19.63 & 0.00 & 37 & 432.01 & 373424.06 \\
\hline 16 & Drainage Material & & 19.63 & 0.00 & 37 & 540.24 & 583475.10 \\
\hline 10 & New Embankment Material & & 18.06 & 43.09 & 30 & 274.39 & 138495.18 \\
\hline 17 & New Embankment Material & & 18.06 & 43.09 & 30 & 365.85 & 246213.66 \\
\hline 18 & New Embankment Material & & 18.06 & 43.09 & 30 & 420.73 & 325617.60 \\
\hline 19 & New Embankment Material & & 18.06 & 43.09 & 30 & 457.32 & 384708.84 \\
\hline
\end{tabular}

target spectrum. Earthquake records whose response spectrum matches approximately the target spectrum were taken into consideration. Also, seismic moment magnitudes between 7 and 8 were inputted as parameters during the search. According to Wood et al. [20], the faults around the island of Puerto Rico can generate earthquakes with maximum magnitudes ranging between $M 7.0$ to $M 7.5$. Table 2 shows the characteristics of the earthquake records selected for the analyses (name, year, station, 5-95\% duration, arias intensity, moment magnitude, and time step-dt). The Significant Duration [15] defines ground motion duration as the length of the time interval between the accumulation of 5 and $95 \%$ of ground motion energy, where ground motion energy is defined by the Arias Intensity [2]. The Arias Intensity (IA) is a measure that describes the strength and potential destructiveness of an earthquake. Three acceleration time histories were selected in order to have variation of ground motion characteristics. Figure 6 shows the acceleration time histories with their Fourier spectrums used in the analyses.

\section{Results from the applied performance displacement based methodology}

The dynamic analyses were performed using the three earthquake records shown in Table 2. Each of the records were multiplied by factors varied from 0.5 to $1.5 \mathrm{~g}$ as shown in Table 3 to perform an incremental dynamic analysis. Maximum acceleration and horizontal displacements values at the top of the core are shown also in Table 3 and were obtained from the dynamic analyses. Peak ground acceleration values (PGA) are shown for the input records. Equation (9) was used to calculate expected moment magnitude $(\mathrm{Mw})$ that will develop the dam system displacement level obtained from the dynamic analyses according to the different PGA values. Then, Eq. (10) was solved for $r$ to obtain the epicentral distance or nearest distance to the fault plane for the calculated value of seismic moment magnitude (Mw). Figures 7 and 8 shows a comparison of the moment magnitudes and epicentral distance obtained for the different displacement or damage levels in Carite Dam for the three earthquake records considered. Taking into consideration ASCE 1 and ASCE 2 cases that have similar PGA values, maximum horizontal displacements obtained were larger for ASCE 1 case which traduces in higher $\mathrm{Mw}$ 

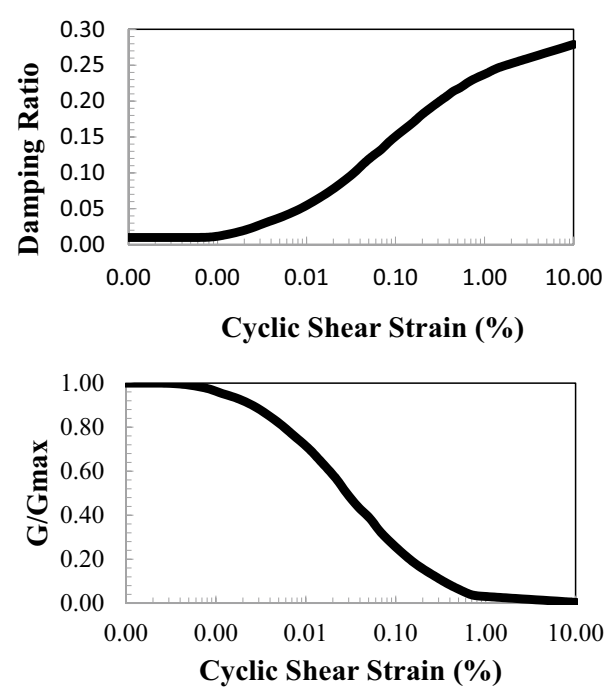

Fig. 4 G/Gmax reduction and damping curves

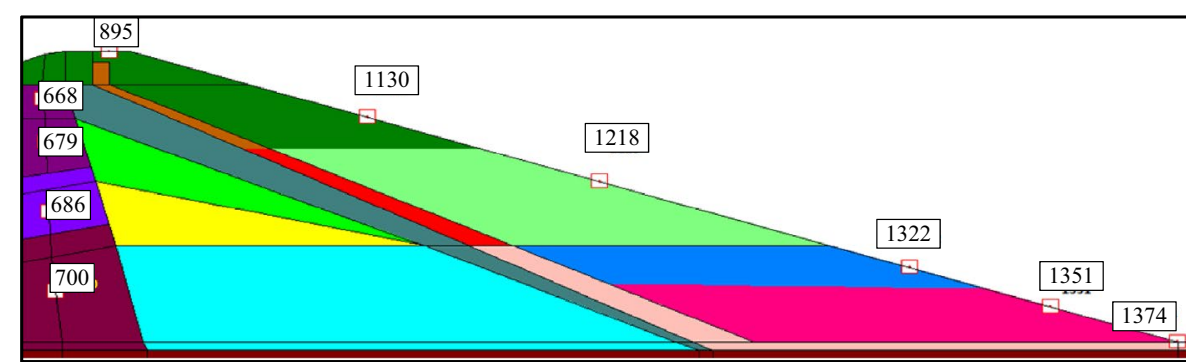

Fig. 5 Material properties with node histories

needed to attain the displacement level. The differences obtained from each case are due to the inherent different earthquake characteristics among earthquake records such as duration of strong motion, arias intensity, frequency content and cumulative absolute velocity. Higher variability was obtained using the equation to compute the epicentral distance. However, this methodology presents an excellent way to relate displacements to $\mathrm{Mw}$ and $\mathrm{r}$ to approximately obtain an idea of what earthquake will impact the dam. Further evaluation will be needed, but the method shows good promise.

Table 2 Seismic records used in the dynamic analyses

\begin{tabular}{lllllllll}
\hline Case & $\begin{array}{l}\text { Earthquake } \\
\text { name }\end{array}$ & Year & Station name & $\begin{array}{l}\mathbf{5 - 7 5 \%} \\
\text { duration } \\
\mathbf{( s )}\end{array}$ & $\begin{array}{l}\mathbf{5 - 9 5 \%} \\
\text { duration } \\
\mathbf{( s )}\end{array}$ & $\begin{array}{l}\text { Arias } \\
\text { intensity } \\
\text { (m/s) }\end{array}$ & Magnitude & dt (s) \\
\hline ASCE 1 "KocaeliTurkey" & 1999 & "Gebze" & 6.1 & 11.8 & 1.3 & 7.51 & 0.005 \\
ASCE 2 "Cape Mendo- & 1992 & $\begin{array}{c}\text { "Ferndale Fire } \\
\text { Cino" }\end{array}$ & 6.2 & 13.6 & 1.7 & 7.01 & 0.005 \\
ASCE 3 & "Chi-Chitainan" & 1999 & "TCU067" & 11 & 23 & 3.6 & 7.62 & 0.005 \\
\hline
\end{tabular}




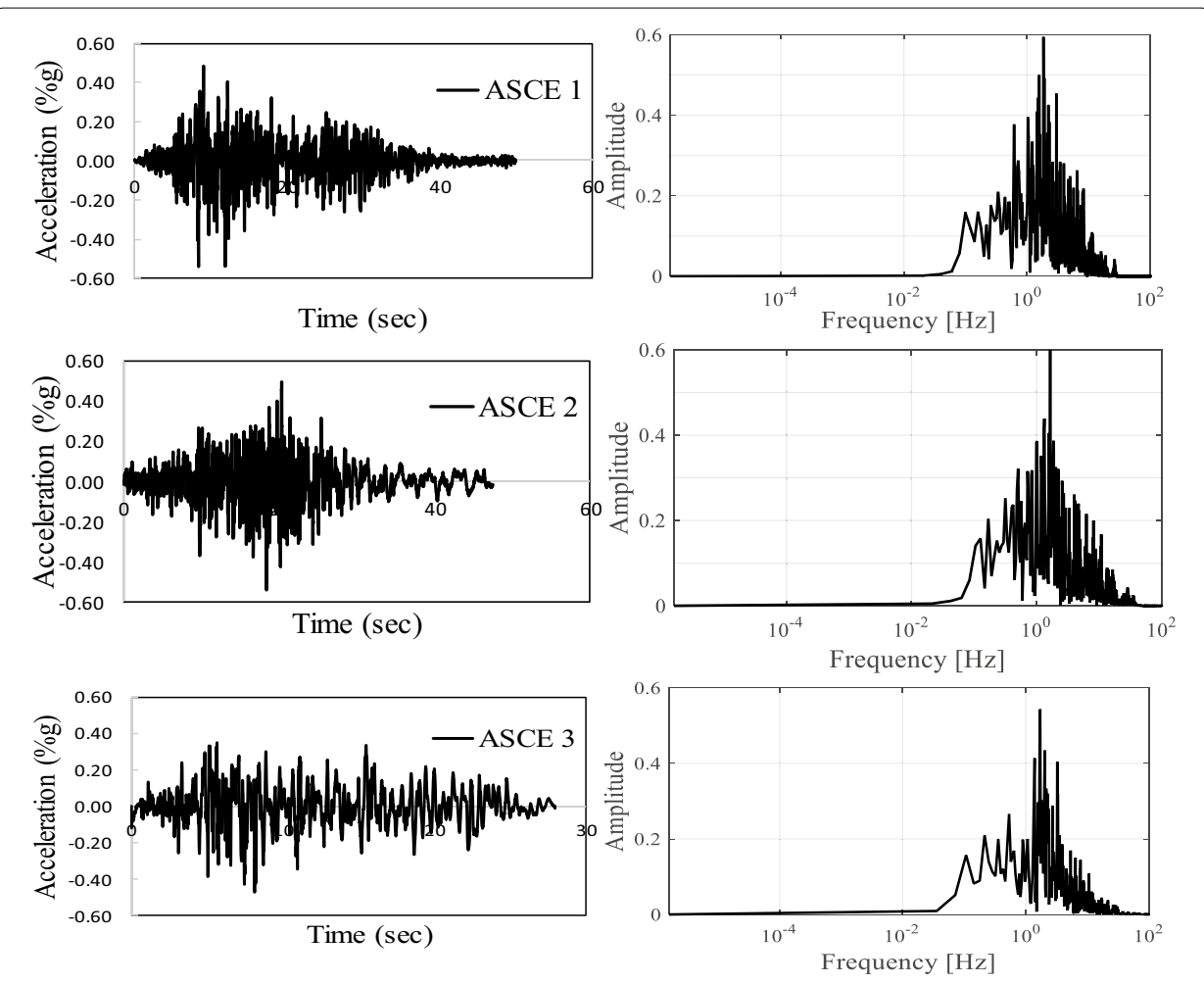

Fig. 6 Acceleration time histories with their Fourier spectrums

Table 3 Maximum response values and displacement-based methodology application

\begin{tabular}{llllllrr}
\hline CASE & Factor (PGA) & PGA & $\begin{array}{l}\text { Max acceleration } \\
(\mathbf{\% g})\end{array}$ & $\begin{array}{l}\text { Max spectral } \\
\text { acceleration }(\mathbf{\% g})\end{array}$ & $\begin{array}{l}\text { Max displacement } \\
(\mathbf{m})\end{array}$ & $\mathbf{M w}$ & $\mathbf{r}(\mathbf{k m})$ \\
\hline ASCE 1 & 0.5 & 0.27 & 0.795 & 2.344 & 0.336 & 5.99 & 2.57 \\
& 1 & 0.54 & 1.270 & 4.08 & 0.659 & 6.96 & 12.23 \\
& 1.25 & 0.675 & 1.371 & 3.897 & 0.792 & 7.23 & 18.95 \\
& 1.5 & 0.81 & 1.454 & 4.981 & 0.985 & 7.54 & 31.10 \\
ASCE 2 & 0.5 & 0.27 & 0.821 & 2.899 & 0.211 & 5.31 & 0.86 \\
& 1 & 0.54 & 0.826 & 2.848 & 0.457 & 6.43 & 5.20 \\
& 1.25 & 0.675 & 0.804 & 2.483 & 0.607 & 6.84 & 10.07 \\
& 1.5 & 0.81 & 0.893 & 2.820 & 0.755 & 7.16 & 16.91 \\
ASCE 3 & 0.5 & 0.235 & 0.611 & 2.494 & 0.394 & 6.22 & 3.72 \\
& 1 & 0.47 & 0.844 & 3.151 & 0.780 & 7.21 & 18.36 \\
& 1.25 & 0.5875 & 0.831 & 2.806 & 0.966 & 7.51 & 29.60 \\
& 1.5 & 0.705 & 0.939 & 2.943 & 1.153 & 7.77 & 45.10 \\
\hline
\end{tabular}

\section{Conclusions}

A performance displacement based methodology was applied to a case study of an earth dam. The methodology consists in related the systems displacements to moment magnitudes and epicentral distance to have an idea of the earthquake that will developed certain limit state based on displacements. This method has never been applied to an earth dam, only to RC frame buildings. The methodology calculated the moment magnitude needed to attain a maximum displacement in the top of the dam. Differences were obtained among 


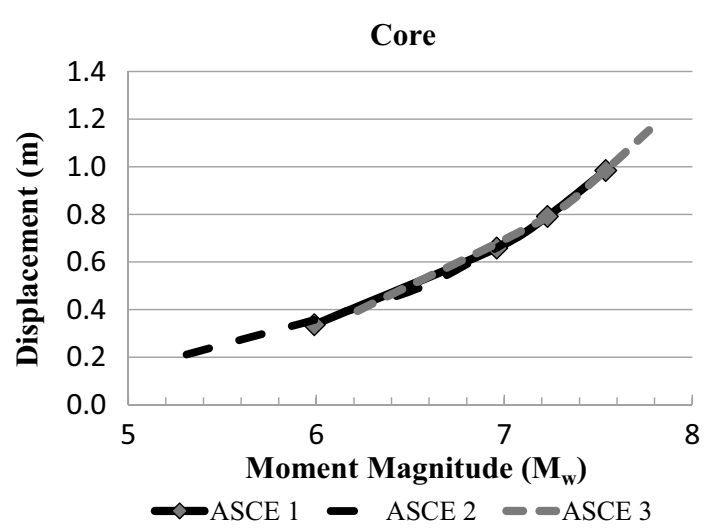

Fig. 7 Displacements in function of $\mathrm{Mw}$

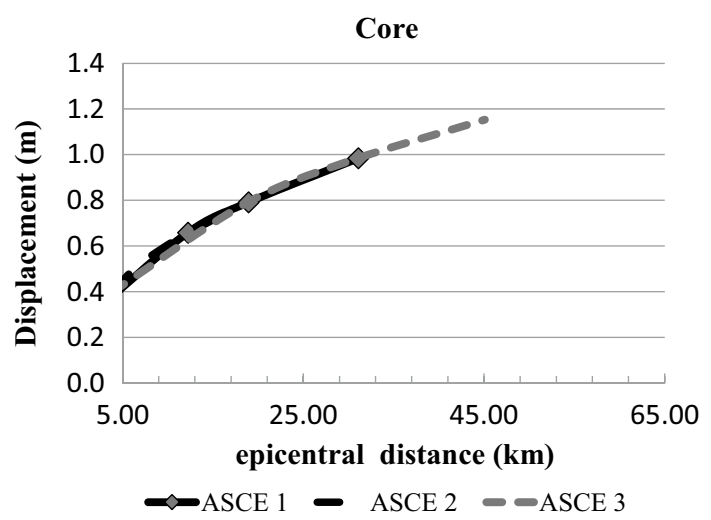

Fig. 8 Displacements in function of epicentral distance

the three earthquake records considered in this study due to the variability in earthquake characteristics. It is recommended to evaluate a dam with at least 7 earthquake records to have a better idea of what $\mathrm{Mw}$ will really impact a particular limit state. This can be use with an alert system to trigger emergency measurements for an earthquake event in a dam site.

Authors' contribution

Both authors participate in the analyses and writting of the paper. Both authors read and approved the final manuscript.

Author details

${ }^{1}$ US Army Corps of Engineers, 701 San Marco Blvd., Jacksonville, FL 32207, USA. ${ }^{2}$ University of Puerto Rico at Mayaguez, Call Box 9000, Mayaguez, PR 00681, USA.

Acknowledgements

This work was funded by the Puerto Rico Strong Motion Program and the Power Authority of Puerto Rico.

Competing interests

The authors declare that they have no competing interests.

\section{Publisher's Note}

Springer Nature remains neutral with regard to jurisdictional claims in published maps and institutional affiliations.

Received: 8 June 2016 Accepted: 25 May 2017

Published online: 05 June 2017 


\section{References}

1. Andrianpoulos Kl, Papadimitriou AG, Bouckovalas GD, Karamitros DK (2014) Insight into the seismic response of earth dams with an emphasis on seismic coefficient estimation. Comput Geotech 55:195-210

2. Arias A (1970) A measure of earthquake intensity. In: Hansen RJ (ed) Seismic design for nuclear power plants. MIT Press, Cambridge, pp 438-483

3. ASCE 7-10 (2010) Minimum design loads for buildings and other structures. American Society of Civil Engineers, ASCE, Reston

4. Faccioli E, Paolucci R, Reyb J (2004) Displacement spectra for long periods. Earthquake Spectra 20(2):346-376

5. FEMA 65 (2005) Federal guidelines for dam safety: earthquake analyses and design of dams. May 2005. Washington, $D C, p 75$

6. FEMA 1025 (2015) Federal guidelines for dam safety risk management. January 2015. Washington, DC, p 49

7. ICOLD (2010) Selecting seismic parameters for large dams. Guidelines Revision of Bulletin 72 , Committee on Seismic Aspects of Dam Design, International Commission on Large Dams, Paris

8. Kramer S (1996) Geotechnical earthquake engineering. Prentice Hall, Upper Saddle River, p 438

9. Mehaan CL, Vahedifard F (2013) Evaluation of simplified methods for predicting earthquake-induced slope displacements in earth dams and embankments. Eng Geol 152:180-193

10. NEHRP (1997) Commentary on the guidelines for the seismic rehabilitation of buildings. FEMA 274

11. Ohta Y, Goto N (1978) Empirical shear wave velocity equations in terms of characteristic soil indexes. Earthq Eng Struct Dyn 6(2):167-187

12. Papadimitriou AG, Bouckovalas GD, Andrianpoulos KI (2014) Methodology for estimating seismic coefficients for performance-based design of earth dams and tall embankments. Soil Dyn Earthq Eng 56:57-73

13. Priestley MJN, Calvi GM, Kowalsky MJ (2007) Displacement-based seismic design of structures. IUSS press, Pavia, p 721

14. SEAOC (1995) Vision 2000: performance based seismic engineering of buildings, vol I and II. April 1995. San Francisco

15. Trifunac MD, Brady AG (1975) A study on the duration of strong earthquake ground motion. Bull Seismol Soc Am 65:581-626

16. Vidot-Vega AL (2008) The impact of load history on deformation limit states for the displacement-based seismic design of RC moment frame buildings. Ph.D. Dissertation, Department of Civil, Construction and Environmental Engineering, NCSU, Raleigh

17. Vucetic M, Dobry R (1991) Effect of soil plasticity on cyclic response. J Geotech Eng 117(1):89-107

18. Wieland M (2012) Seismic design and performance criteria for large storage dams. Proceedings of the 15 world conference in earthquake engineering, Lisbon

19. Wieland M, Brenner RP, Bozovic A (2008) Potentially active faults in the foundations of large dams, part l: vulnerability of dams to seismic movements in dam foundation. Special Session S13. Proceedings 14th world conference on earthquake engineering, Beijing

20. Wood CK, Liu P, King V, Su F, Piety LA (2014) Probabilistic seismic hazard analysis and time histories for Guayabal, Dam, Puerto Rico. BUREAU OF RECLAMATION, Technical Service Center Denver, Colorado, Seismotectonics and Geophysics Group, 85-833000

\section{Submit your manuscript to a SpringerOpen ${ }^{\circ}$ journal and benefit from:}

- Convenient online submission

- Rigorous peer review

- Immediate publication on acceptance

Open access: articles freely available online

- High visibility within the field

- Retaining the copyright to your article

Submit your next manuscript at $>$ springeropen.com 